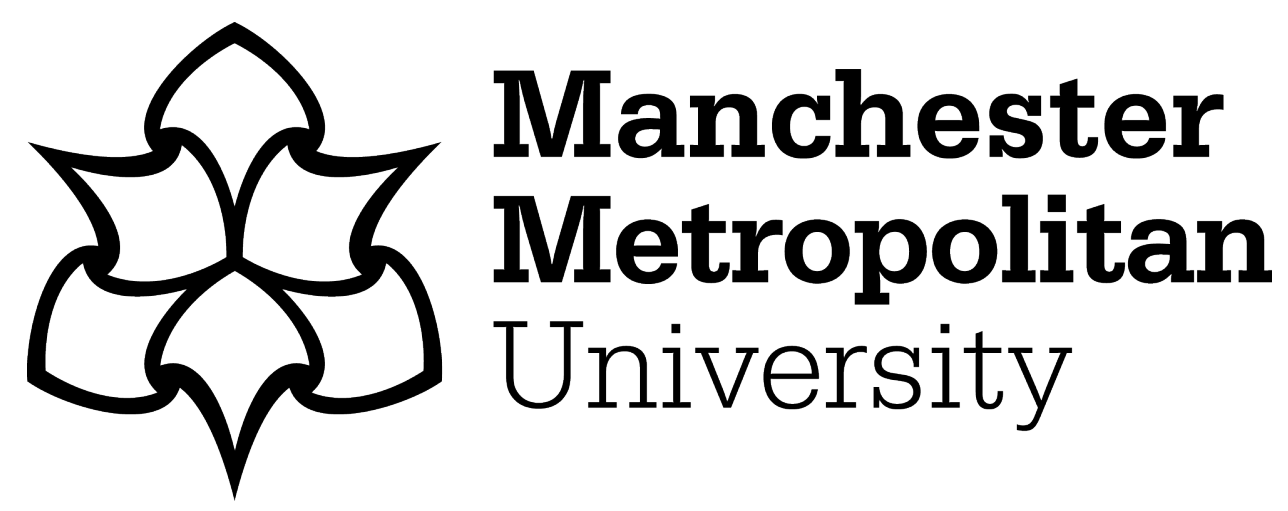

Wazaify, M, Al-Afifi, M, Kewley, S, Quigg, Z, Whitfield, M, McVeigh, J ORCID logoORCID: https://orcid.org/0000-0001-5319-6885 and Van Hout, MC (2020) Perspectives of frontline professionals on Palestinian children living with sibling and parental drug use in the UNRWA camps, Jordan. International Journal of Mental Health and Addiction, 18 (6). pp. 1620-1637. ISSN 1557-1874

Downloaded from: https://e-space.mmu.ac.uk/625620/

Version: Accepted Version

Publisher: Springer Verlag

DOI: https://doi.org/10.1007/s11469-020-00293-1

Please cite the published version 


\section{International Journal of Mental Health and Addiction \\ Perspectives of frontline professionals on Palestinian children living with sibling and parental drug use in the UNRWA camps, Jordan

\author{
--Manuscript Draft--
}

Manuscript Number:

Full Title:

Article Type:

Keywords:

Corresponding Author:

Corresponding Author Secondary

Information:

Corresponding Author's Institution:

University of Jordan

Corresponding Author's Secondary Institution:

First Author:

Mayyada Wazaify

First Author Secondary Information:

Order of Authors:

Mayyada Wazaify

Leen Abushams

Mohammad Al-Afifi

Stephanie Kewley

Zara Quigg

Mark Whitfield

Jim McVeigh

Marie Claire Van Hout

Order of Authors Secondary Information:

Funding Information:

Liverpool John Moores University

Prof Marie Claire Van Hout

Context: The occupied Palestinian territories (oPt) consists of the non-contiguous West Bank including East Jerusalem and the Gaza Strip. It is densely populated within these confines, and has a unique socio-economic context characterized by political and economic tensions. Around 2.2 million Palestinians are displaced and living in the ten UNRWA refugee camps in Jordan. Palestinian communities are exposed to a double burden of disease caused by the severe economic, social and health consequences of Israeli occupation and resultant displacement. Exposure to political violence, economic hardship, fragmentation of Palestinian families, unemployment, trauma and community stress underpin a reported rise in drug abuse.

Method: A qualitative study using focus groups ( $n=3$ ) with a convenience sample of health care and educational professionals was conducted in two UNRWA camps ( AlZarka, Al-Wehdat ) in Jordan. Guided discussions explored the experiences of these professionals in working with Palestinian families and children affected by substance/drug use and drug use disorder in the home. Data were analysed using thematic analysis (TA).

Results: Five themes emerged from the TA. These were: 1)Access to drugs was perceived to be relatively easy in the camps; 2) Attitudes towards drugs appear to have desensitised, yet stigma persists; 3) Families of drug users are affected by fear, social and economic poverty, with significant physical and psychological cost to children; 4) 
Causes of substance/drug use in Palestinian communities living in Jordanian UNRWA camps is multifactorial; 5) Solutions are multi-faceted and indicative of the need for prevention and support for those at risk, and affected .

Conclusions: Threats to UNRWA from the current political climate and the reducing investment in services may exacerbate this public health and security issue. For an evidence based approach to have credibility in the camp communities, there is a need for accurate, factual information, along with robust epidemiological data, relating to the extent, characteristics and harms associated with drug use.

\section{Response to Reviewers:}

Response to Reviewers:

First of all, we would like to thank the editor and both reviewers for their time, effort and valuable comments.

The authors have addressed all comments as follows (all changes are either in yellow highlight or strikethrough):

Reviewer \#1:

Dear Dr. Masood,

Thank you for considering me as a reviewer for this paper entitled "Perspectives of frontline professionals on Palestinian children living with sibling and parental drug use in the UNRWA camps, Jordan". In my opinion, the paper is well written and contributes to the existing knowledge. I could not find any logical errors in the presentation and the approaches used. The following points may be considered while revising the article. - Abstract (Page1): Five million Palestinians live in the oPt (2 million in Gaza, with $66.2 \%$ in refugee camps, and 3 million in the West Bank and Jerusalem, with $26.6 \%$ in refugee camps). A further 2.2 million Palestinians are displaced and living in the ten UNRWA refugee camps in Jordan. Citation needed.

>> This sentence has been deleted upon request of reviewer-2

- Page 3, Lines (2- 8) were just stated in abstract.

>> Sentence deleted.

-Page 3, Lines 5. Citation needed.

-Page 3, Lines 10. Citation needed.

- Page 3, Lines 12. Citation needed.

-Page 3, Lines 17. Citation needed.

-Page 3, Lines 17. Citation needed.

- Page 4, Line 9. Please follow the APA format in text citation.

- Page 5, Line 11. Please follow the APA format in text citation.

- Page 22, Line 4. Citation needed.

>> All citations have been added in place as requested. APA format have been addressed.

- Introduction: The effect of drug use on Palestinian refugee children needs to be more clarified and linking within the existing literature.

>> This paragraph has been added as requested in pages 4-5:

"The effect of drug use on children and their families living in the Palestinian refugee camps is far -reaching and includes familial stigma and community isolation, dysfunction, early school leaving and maladaptive child development (Van Hout et al., 2019). Research conducted by the team in 2019 in the oPt has underscored how they are vulnerable of children and young people at risk of substance use (including drugs), and are vulnerable to physical and sexual abuse, exploitation in drug trafficking, and at risk of becoming dependent users themselves (Al-Afifi et al., 2015; Van Hout et al., 2019; (Al-Afifi et al., 2019; United Nations Office on Drugs and Crime (UNODC), 2019)."

Reviewer 2: (THE COMMENNTS WERE IMPEDED WITHIN pdf)

-Abstract: No need for this sentence in the abstract and Introduction:

> > > A sentence has been deleted from both the abstract and Introduction upon request. "Five million Palestinians live in the oPt (2 million in Gaza, with $66.2 \%$ in refugee camps, and 3 million in the West Bank and Jerusalem, with $26.6 \%$ in refugee camps). A further 2.2 million Palestinians are displaced and living in the ten UNRWA refugee camps in Jordan."

-Introduction, page 4, line 8: Need citation

>> A citation (UNRWA, 2020a) has been added to this sentence "UNRWA is the 
oldest....." as requested.

-AUTHOR RESPONSE: Page 4: Variables have been separated as requested: "A reported rise in substance/drug use, injecting use and drug use disorder in the oPt (West Bank and Gaza) has been observed in recent times and related to exposure to trauma, poverty, unemployment, fragmentation of Palestinian families and community stress"

-AUTHOR RESPONSE: Pages 6-7: This sentence has been added to describe the rationale and uniqueness of the study as requsted: "To date these has not been any published study on the situation of drug use and drug use disorder in the Jordanian UNRWA camps. Our study offers a preliminary investigation of the issue and how it affected Palestinian communities who live there, in order to understand their needs and inform the strategic response."

-my recommendation to divide the discussion to the important findings, and need to discuss them separately according to sub- topics in the results section > > AUTHOR RESPONSE: The results themes are 1)Access to drugs was perceived to be relatively easy in the camps; 2) Attitudes towards drugs appear to have desensitised, yet stigma persists; 3) Families of drug users are affected by fear, social and economic poverty, with significant physical and psychological cost to children; 4) Causes of substance/drug use in Palestinian communities living in Jordanian UNRWA camps is multifactorial; 5) Solutions are multi-faceted and indicative of the need for prevention and support for those at risk, and affected.

>> We present the discussion in the same themes, relating to change in in exposure, availability and desensitisation toward drugs, and Jordanian societal trends in substance use (para 2); the differences in perspective on the issue, and the consequences of this phenomenon (para 3), and the strategic responses and context for reform (para 4).

-Conclusions: there is need to connect these conclusions with mental health > > AUTHOR RESPONSE: ADDRESSED

-Conclusions: there is need to write the study limitations, need to expand the conclusions of the study and its implications, in addition to recommendations for continuing studies

>> AUTHOR RESPONSE: ADDRESSED

-References: journals and books need tobe italic. There is a need to check carefully this section

$\rightarrow>>$ AUTHOR RESPONSE: ADDRESSED

->> Also 2 additional references: UNRWA, 2020a and UNRWA, 2020b have been added.

-With regard to Tables: APA style: without vertical lines and must be just with three horizontal lines

->>>> AUTHOR RESPONSE Addressed

$-$

$-$

$-$ 
Title:

Perspectives of frontline professionals on Palestinian children living with sibling and parental drug use in the UNRWA camps, Jordan

\section{Author Listing}

Mayyada Wazaify, Professor, School of Pharmacy, University of Jordan, Jordan email: m.wazaify@ju.edu.jo

Leen Abushams, Researcher, School of Pharmacy, University of Jordan, Jordan Email: leen_abushams@hotmail.com

Mohammed Al-Afifi, Director, Substance Abuse Research Centre (SARC), Palestine Email: m.afifi47@gmail.com

Stephanie Kewley, Senior Lecturer Forensic Psychology, School of Science, Liverpool John Moore's University, UK email: s.kewley@ljmu.ac.uk

Zara Quigg, Reader of Behavioural Epidemiology, Public Health Institute (PHI), Liverpool John Moore's University, UK email: z.a.quigg@ljmu.ac.uk

Mark Whitfield, Intelligence and Surveillance Manager, Public Health Institute (PHI), Liverpool John Moore's University, UK email:m.whitfield@ljmu.ac.uk

Jim McVeigh, Professor, Substance Use and Associated Behaviours, Department of Sociology, Manchester Metropolitan University, UK email: j.mcveigh@mmu.ac.uk

Marie Claire Van Hout, Professor, Public Health Institute (PHI), Liverpool John Moore's University UK email: m.c.vanhout@ljmu.ac.uk 


\section{Corresponding Author:}

Mayyada Wazaify, Professor, School of Pharmacy, University of Jordan, Jordan email: m.wazaify@ju.edu.jo 
Title:

Perspectives of frontline professionals on Palestinian children living with sibling and parental drug use in the UNRWA camps, Jordan

\section{Abstract}

Context: The occupied Palestinian territories (oPt) consists of the non-contiguous West Bank including East Jerusalem and the Gaza Strip. It is densely populated within these confines, and has a unique socio-economic context characterized by political and economic tensions. Around 2.2 million Palestinians are displaced and living in the ten UNRWA refugee camps in Jordan. Palestinian communities are exposed to a double burden of disease caused by the severe economic, social and health consequences of Israeli occupation and resultant displacement. Exposure to political violence, economic hardship, fragmentation of Palestinian families, unemployment, trauma and community stress underpin a reported rise in drug abuse.

Method: A qualitative study using focus groups $(n=3)$ with a convenience sample of health care and educational professionals was conducted in two UNRWA camps (Al-Zarka, Al-Wehdat) in Jordan. Guided discussions explored the experiences of these professionals in working with Palestinian families and children affected by substance/drug use and drug use disorder in the home. Data were analysed using thematic analysis (TA).

Results: Five themes emerged from the TA. These were: 1)Access to drugs was perceived to be relatively easy in the camps; 2) Attitudes towards drugs appear to have desensitised, yet stigma persists; 3) Families of drug users are affected by fear, social and economic poverty, with significant physical and psychological cost to children; 4) Causes of substance/drug use in Palestinian communities living in Jordanian UNRWA camps is multifactorial; 5) Solutions are multi-faceted and indicative of the need for prevention and support for those at risk, and affected. 
Conclusions: Threats to UNRWA from the current political climate and the reducing investment in services may exacerbate this public health and security issue. For an evidence based approach to have credibility in the camp communities, there is a need for accurate, factual information, along with robust epidemiological data, relating to the extent, characteristics and harms associated with drug use.

\section{Key Words}

UNRWA, Palestinian refugees, drugs, Jordan 


\section{Introduction}

The occupied Palestinian territories (oPt) consists of the non-contiguous West Bank including East Jerusalem and the Gaza Strip. It is densely populated within these confines, and has a unique socio-economic context characterized by political and economic tensions. In total, the estimated number of internally and externally displaced Palestinian refugees registered under the United Nations Relief and Works Agency (UNRWA) is estimated to be 5.59 million across the West Bank, Gaza Strip, Jordan, Lebanon and Syria (UNRWA, 2020a). UNRWA is the oldest temporary agency of the United Nations (UN), created in response to the Palestinian refugee crisis in 1948. It has a focused mandate which is to deal with the Palestinian refugee crisis, and in so doing is different to other UN agencies which operate with a broad and global focus (UNRWA, 2020a). It has provided support (education, health, relief and social services) to Palestinians in five fields of operation: Jordan, Lebanon, Syria, Gaza Strip and the West Bank since the 1950s (UNRWA, 2020a). Jordan hosts the largest number of Palestinian refugees amongst the UNRWA areas, with 2,026, 736 registered refugees living in ten camps (UNRWA, 2020). According to UNRWA, Palestine refugees in Jordan are eligible for temporary Jordanian passports, however these do not entitle them to full citizenship rights (for example the right to vote and employment with the government (UNRWA, 2020b). Hence, given their living conditions and lack of basic civil rights,-Palestinian communities are exposed to a double burden of disease caused by the severe economic, social and health consequences of conflict and violence, occupation, high levels of poverty, and other social determinants of health such as displacement which jeopardize their health outcomes and wellbeing (Kitamura et al., 2018). For those displaced into the Jordanian UNRWA camps, there are increasing rates of non-communicable diseases and mental health conditions, with their health needs primarily met by 138 primary care clinics provided by UNRWA (Santoro at al., 2016; Kitamura et al., 
2018). In 2020, however UNRWA continues to tackle overcrowding and the severe funding crisis.

Research on health risk behaviours relating to substance/drug use and injecting use of drugs in the Middle East and North Africa (MENA) region remains scant, with little early warning data to inform government responses to emerging public health threats (Arfken \& Ahmed, 2016; Glick et al., 2018). A reported rise in substance/drug use, injecting use and drug use disorder in the oPt (West Bank and Gaza) has been observed in recent times and related to exposure to trauma, poverty, unemployment, fragmentation of Palestinian families and community stress (Sweileh et al., 2004; Al-Afifi et al., 2015; Massad et al., 2016; Palestinian National Institute of Public Health, 2017a; Damiri at al., 2018a;b; Van Hout et al., 2019). These observed increases have occurred despite religious, legal, and cultural constraints (Al-Afifi et al., 2019). Situation assessments in the oPt have highlighted the rise in novel psychoactive substances (NPS) ('Sintetique Marijuana'), high dose use of methadone, morphine, phencyclidine, barbiturates, benzodiazepines, synthetic opioids such as tramadol, and gabapentinoid drugs such as pregabalin, and marijuana, prescription medications (antidepressants, Z-hypnotics, benzodiazepines and analgesics (Palestinian National Institute of Public Health, 2017a). The effect of drug use on children and their families living in the Palestinian refugee camps is far -reaching and includes familial stigma and community isolation, dysfunction, early school leaving and maladaptive child development (Van Hout et al., 2019). Research conducted by the team in 2019 in the oPt has underscored how they are vulnerable to physical and sexual abuse, exploitation in drug trafficking, and at risk of becoming dependent users themselves (Al-Afifi et al., 2015; Van Hout et al., 2019; (Al-Afifi et al., 2019; United Nations Office on Drugs and Crime (UNODC), 2019). Risk behaviours related to drugs are higher in Palestinian refugee camps, urban areas and among older male youth (Thabet \& Dajani, 2012; Glick et al., 2018). This vulnerability heightens the potential 
for drug exposed and traumatised Palestinian children (for example anxiety disorder, PTSD) to use drugs themselves, risk overdose, psychiatric events, and HIV/Hepatitis C acquisition (Khamis, 2005; Defense for Children International/Palestine Section, 2007; Al- Krenawi et al., 2007; Elbedour et al., 2007; Al-ghzawi et al., 2014; Van Hout et al., 2019).

To date, across the border in neighbouring Jordan, very little is known about substance/drug use types, patterns, rates of substance/drug use disorder, and levels of injecting drug use and related blood borne infections among externally displaced Palestinian communities in the UNRWA camps. Jordan is considered as a transit country for opiates, cannabis, and synthetic drugs, with a small population of drug users with prescription drugs such as pregabalin and opthalmic drugs, volatile substances, NPS such as synthetic marijuana, stimulants, opium and heroin most commonly abused (de La Rochefoucauld, 2014; Wazaifyet al., 2017; Al-Husseini et al., 2018a; b; Al-Husseini et al., 2019; Al-Khalaileh et al., 2019) There are news reports of rising rates of injecting drug use and substance/drug use disorder, all underpinned by poor living conditions, poverty, lack of job opportunities, and the establishment of drug trafficking networks in some UNRWA refugee camps such as Al Husn, located 80km north of Amman (Dupire, 2018). To date these has not been any published study on the situation of drug use and drug use disorder in the Jordanian UNRWA camps. Our study offers a preliminary investigation of the issue and how it affected Palestinian communities who live there, in order to understand their needs and inform the strategic response. Hence in order to better understand their needs, the study aimed to explore the perspectives of healthcare and educational professionals working for UNRWA in two camps, namely Al-Zarka and AlWehdat. 


\section{Methods}

A qualitative study was conducted using focus groups (FG) (n=3) with health care and educational professionals working in two UNRWA camps (Al-Zarka, Al-Wehdat). The FG explored the experiences and knowledge of professionals working with Palestinian families and children affected by substance/drug use and drug use disorder in the home. Ethical approval for the study was granted by the University Ethics Committee at Liverpool John Moores University, UK (approval number 19/PHI/005) with further ethical approval granted by the Deanship of Scientific Research at the University of Jordan, Jordan (approval number 413/2019/19) .

The design of the FG guide was based on research expertise in the field, existing work by team members in both the Gaza Strip and the West Bank (Al-Afifi et al., 2019; Van Hout et al., 2019) and on a systematic review of literature conducted by the team (Van Hout et al., 2019). Participants were recruited purposively through personal contact with the headquarter and field office of UNRWA in Jordan. Eligibility criteria meant that all participants were over the age of 18 and employed in health care professional or educational roles at refugee camp facilities. Potential participants were sent an information sheet about the study and offered an opportunity to ask further questions about the study before agreeing to participate. Before participating, participants signed a consent form. Participants did not receive any incentive or compensation for participation.

FG were conducted by two members of the team, a facilitator (MW) and co-facilitator (LA), were audio recorded and supported by note taking. Open-ended questions (Smithson, 2000; Kallio et al., 2016) were posited by the FG facilitator. Participants were asked to describe the following: 'the current situation with regard to substanceldrug use, risk behaviours such as injecting drug use, and substanceldrug use disorder in refugee camps in Jordan'; 'how this situation has changed over time'; 'how this currently affects Palestinian families and children 
(if any)'. In addition to discussion focusing on the current situation in the refugee camps, the FG facilitator also explored participants thoughts around possible community and psychosocial interventions needed to reduce the vulnerability of children who might be exposed to substance/drugs, and parental/sibling drug use or drug use disorder, and how non-governmental organisations (NGOs) such as UNRWA and other international organisations might better support Palestinian families and children affected by this issue, was also asked. All FG were audio recorded and fully transcribed into Arabic, and then translated into English by the second author. This was cross-checked for accuracy by the lead author, prior to analysis.

Data were analysed using thematic analysis (TA); (Braun et al., 2019). This approach was deemed suited to garner in depth understanding of the impacts of familial drug abuse within the multifaceted socio-political context of Palestinian families living in refugee camps in Jordan. It underpins phenomenological examination of the experiences of professionals working with Palestinian families and children, (Al-Afifi et al., 2019) from a range of multidisciplinary perspectives, realities and meanings, due to its mitigation of potential cultural and language misinterpretation, and appreciation of the complex social contexts and challenges faced by participants (Braun \& Clarke, 2006; Nowell et al., 2017; Clarke \& Braun, 2018). In order to ensure scientific rigour, a quality framework in analysis was used (Braun \& Clarke, 2006). This involved several key steps: (1) reading and rereading the transcription, individually and in pairs to note early ideas; (2) coding in a systematic and logical manner using a datadriven approach supported by software program QSR NVivo version 12, and paying attention to interesting concepts and ideas within the data; (3) organisation of codes into corresponding groups using an iterative process in developing themes and subthemes; (4) refining and reviewing of themes by the team as a collective in terms of internal homogeneity and external heterogeneity, examination of coherence of patterns across themes and development of a 
thematic map; and (5) final clear definition and naming of themes, with data extracts representing and articulating the essence of the theme, and overall analysis.

\section{Results}

Three FG were undertaken in two Jordanian UNRWA camps; Al-Zarqa camp (with health care professionals in a mixed gender FG) and in Al-Wehdat camp (with school teachers, principals and counsellors in two gender specific FG). A total of 20 participants took part, each FG lasted on average $69 \min (\mathrm{SD}=4.0)$. Table One ( I) provides an overview of participants' demographics and focus group details. Five key themes emerged from the thematic analysis of the three focus groups, which are detailed along with their corresponding sub themes in Table Two ( II). In addition to these themes, participants provided details of the most common type of substances being used, which are listed in Table Three (III).

Insert Tables I, II and IIIabout here.

\section{Access to drugs was perceived to be relatively easy in the camps}

Across all three FG, discussion centred on children's access to and witnessing of drug use within UNRWA camps. Participants noted how vulnerable children are. One school nurse highlighted how children are often the target within their family and within the camp, especially when they are perceived to be vulnerable: "the impression inside the camp, if you are not strong enough you will not survive, and a lot of people will get at you" (FG3 SNF). Some perceived that drug dealing activity was on the increase especially in crowded areas; "sometimes we witness exchange of material in the streets" (FG1 STF). A pharmaceutical assistant illustrated 
how drugs are "being sold as a gum, juice... he [the child] uses the first time like chewing gum which is already a drug then he becomes addict to it" (FG3 PAF). While this form of drug exposure appears to take place outside of the family home, some FG participants reported that mothers of children are also targeted within the home. A practice nurse recalled how she "went through cases where the husband was using and drugged his wife to start using drugs with him by putting drugs for her in juice" (FG3 PNF). In addition to the recruitment of users of drugs there was a belief that those dealing drugs often used these as a weapon to harm others, either by targeting particular families: "if I want to harm a certain family then it will be through drugs" (FG3 PAF) or where children are recruited to sell drugs, dealers will "take advantage of [them] offer them money for distributing or even sexual abuse in return for money" (FG3 PNF).

These issues appear to occur outside school time, while children appeared somewhat protected during school hours. Teachers in two of the FG detailed how they have few concerns around drug use for children who are regularly attending school. One school counsellor reported: "we have about 700 students, out of which only 10-12 families passed by us with an addicted family member to alcohol or other narcotics. This ratio is very low" (FG1 SCF). Some teachers echoed this sentiment recalling "Over the past ten years I had spent here in Al-Wehdat, not a single student with addiction problem had I encountered, and I am very close to the students" (FG1 STF) or "maybe only one time we had only one a case of possession" (FG1 $\mathrm{STF}$ ) and "I never met a student who came up to me and said to me that his father or brother was a user" (FG2 STM). The school janitor noted however that while these problems may not occur in school, at the end of the school day, he observed that people come into the school area in an attempt to try and sell drugs to students, and that this, he reported was almost a daily occurrence: "I witness daily -after the teachers leave because my work ends at 6 PM-where 
no one is there but me, they [outsiders] come to school and start rolling weed, those are not students, they come from out of school and use its' [school's] yard" (FG2 SJM).

Most participants reported that drugs are routinely brought into the camps, one schoolteacher was of the opinion that roadside coffee sellers were creating addicts in taxi drivers by putting "pills in coffee so the driver would come back for this certain kiosk for coffee" (FG2 STM). Other teachers claimed that drug dealers are a result of "intruders who entered the camp, became inhabitants and named themselves residents" (FG1 STF). A school principal described how the situation had changed over time as a result of "too many immigrations from inside to outside and vice versa. The Palestinians inside came out while many people from abroad entered and lived in it, one of them were a group we call 'gypsies', so it became a mixture and different from the way it used to be" (FG1 SPF). This shift in population was not perceived as a positive change; indeed one teacher noted how "original Palestinian families (in the camp) were different and special" (FG1 STF).

Children's exposure to, knowledge and confidence in discussing drug related issues appeared to be increasing, even in younger children who were described as asking school nurses to "tell us about drugs" (FG3 SNF). All three FG spoke about the degrees of exposure and opportunity children of either gender have to access drugs. It was agreed that boys tend to have more opportunity in terms of accessing drugs “because the girl doesn't work while boys do and they are prone to many situations [in the outside world] unlike girls" (FG2 STM); "the male rate (of drug use) is higher because they are more integrated into the society and the surrounding environment" (FG2 STM) and, "he [the boy] can stay out for 10 or 12 hours at night and no one would ask him because he is a boy" (FG3 GPM). However, it was felt that drug use among girls was "more prevalent in rich societies than poor ones. I feel that wealth has a bigger role in addition to their social openness" (FG1 STF). 


\section{Attitudes towards drugs appear to have desensitised, yet stigma persists}

Across all FG, a perception of desensitisation around drug availability and drug use in the camp community was perceived. Participants in the health worker focus group argued how children's knowledge about drugs and access to drugs is widely publicised in social media which they have greater access to. One general practitioner highlighted how social media has "opened the eyes of children wide open to different knowledge" (FG3 GPM), and recalled how education professionals are often "surprised by the amount of information those girls knew... all because social media raised the level of thinking they had" (FG3 GPM). Participants believed that one of the reasons they felt that substance/drug use and drug dependence was more visible was the perceived endorsement from celebrities, one teacher noting how "Celebrities in the past used to be ashamed of addiction, but nowadays they [celebrities or actors] talk about [it] normally in the media and this will help to spread it [normalisation of drug use disorder]" (FG1 STF). Consequently, the nature of drug related activity within the camps was perceived to have proliferated, with sellers using diverse methods of attracting users. A key example was observed by some participants in the Shisha market where sellers "camouflage facts by changing names like the name "ahla nafas" [in English 'sweetest breath'] (FG3 SNF), thus users are unaware of the risks and harms.

Participants were keen to highlight their view that substance/drug use and drug use disorder is a problem across the whole of Jordan, not just in refugee camps: "it is found in most places in Jordan, in Rabieh is in Deir-Ghbar [both are posh areas], it is not exclusive to the camp nor to a certain category" (FG1 SCF). One teacher highlighted how camps are "part of the whole community and the country, we cannot separate them" (FG2 STM), and indeed, "they all suffer from the same factors" (FG1 STF). However, one school nurse disagreed; arguing that camps are unique and separate from the wider community, she stated that most 
communities are more open whereas "the community of the camp is considered closed" (FG3 $\mathrm{SNF}$.

There was debate across the FG regarding the change in the prevalence rates of drug use. One school counsellor argued that "statistically, the situation [drug use] is constant, has not increased nor decreased, there is no increasing. We sense there is an increase because it is religiously and culturally unacceptable, so we exaggerate it and we talk about it as the talk of the time" (FG1 SCF). However, one practice nurse believed that drug use was increasing as her level of awareness had increased and she now "knows things I didn't know before" (FG3 PNF). A school nurse agreed, recalling self-reports from clients who when asked about drug use said: "yes my husband or brother or father is using/addict maybe alcohol, pills or cannabis. So we get from their answers that the numbers are increasing" (FG3 SNF).

In addition to this behaviour change, changes in attitudes towards substance/drug use had also shifted within the camps, with less of a stigma attached to it. One general practitioner provided an analogy to the stigma of smoking Shisha: "in the past it was considered a stigma and shame to smoke shisha, now go to a public place it exists everywhere...it was impossible to meet a girl smoking shisha now it became public and on the sight of employees of the clinic" even in cases where women are pregnant the shame of smoking during pregnancy does not exist her stigma and shame is gone" (FG3 GPM). Both school and practice nurses supported this experience. They illustrated that now in their clinics when gaining personal histories from new patients, they are required to ask "is an addict in the family publicly'. (FG3 SNF). They observed that 'This question wasn't asked in the old days" (FG3 SNF) and "patients respond frankly" (FG3 PNF). They observed that the change in attitude was noticeable in that "in the old days it was rude to ask those kind of questions...we were ashamed to ask" (FG3 GPM). FG however discussed the prevailing stigma around help giving and help seeking. There appeared a dichotomy within the reports of health workers in that the problem is extremely publicised 
across social media yet, "the same local community is hiding it" (FG3 GPM). There appeared a dichotomy within the reports of health workers in that the problem is extremely publicised across social media yet, "the same local community is hiding it" (FG3 GPM). One schoolteacher reported how in "the past when you heard someone is addicted, all the people around him would want to contribute in their treatment and so were their neighbours/family and so on. But nowadays, the situation is so different" (FG1 STF). Societal stigma of substance use and dependence was observed to continue; "some mothers, even if you ask her to discuss something that stigmatizes her son or daughter she refuses, even if they are addicted" (FG3 GPM). A pharmacist also outlined the shame of seeking help, even when a mother knows her son is addicted to drugs "she prefers to take no action like taking her son to the rehabilitation centre or treat addiction because of stigma" (FG3 PAF).

Families of drug users are affected by fear, social and economic poverty, with significant physical and psychological cost to children

FG participants reported how they believed people who use drugs (PWUD) and their drug use disorder, cause families to breakdown socially and economically; that the addiction "leads to poverty and financial crisis" (FG3 APF) and that family members live in fear and distress as they lose "the sense of safety within the family" (FG3 SNF). Participants spoke of the stigma and isolation families experience as a result of drug use, and of how drug use "influences the family reputation" (FG2 SJM) so much so that the user "and his family become isolated and suffer from a stigma... the family is plagued with an addict" (FG2 STM). The stigma was observed to becomes generational, with one general practitioner recalling that " $a$ case of a father addicted to alcohol and always drunk while his children and daughters are all studying and educated and beautiful, but no one would like to propose to his daughters because of his reputation, he became a stigma to them" (FG3 GPM). A school counsellor highlighted how 
poverty is inevitable as "the employer would expel him [addict] if he had found that he [the employee] is a drug user who will then turn to be unable to spend on his family"(FG1 SCF). A teach described how the "money goes to drugs instead of spending it on family, because it is the addicts' priority now" (FG1 STF). Another was of the view that further consequences of drug use disorder was violent crime: "He who drinks or take drugs may kill, for example the doctor we heard about who killed his wife and children, as well as the young man who decapitated his mother because of Joker [street name for synthetic cannabinoids]. All these crimes were because of drugs, killing, raping and others" (FG3 GPM).

Close proximity of PWUD near children was illustrated as resulting in children experiencing a range of significant problems. One teacher concluded children are "ultimately the victim of the whole problem, whether psychologically, health wise, financially or economically" (FG2 STM). Some believed that children experience fear and trauma, and described how one girl is "afraid of her addicted brother which leads her to sleep with the door shut, she lives with anxiety that with time leads to mental illness and problems" (FG3 GPM). Others described occurrence of sexual and violent assaults, "there can be cases of rape, incest and harassment" (FG1 STF); school drop-out "a student told me that he was absent from school, because he was visiting his father in prison, students told me that his father was a drug user that's why he was absent and this had affected his academic achievement" (FG2 STM); and the risk of physical symptoms of secondary inhalation "the smoke will spread in the room just like cigarettes, as a result children in the house will wake up flown away [high] ... Eight years ago I noticed 4th grader little girl in school who was always sleepy, one time I noticed her rolling a piece of paper the same way they roll tobacco, when I asked her what is this she said I want to smoke" (FG1 STF).

Causes of substance/drug use disorder in Palestinian communities living in Jordanian UNRWA camps are multifactorial 
All FG participants agreed that a myriad of factors have facilitated the rise in drug activity in the UNRWA camps in Jordan; instead it was agreed there are many factors at play. Family breakdown and poor parenting were believed to be both causal and consequential factors. One teacher argued this point "well, drug addiction has both economic and cultural sides, most people we mentioned now were former prisoners and left school at a very young age, they grew up and became parents" (FG2 STM). Poor parenting/role models and family breakdown was believed to increase youth risk and vulnerability; "the kid[s] to resort to illegal stuff' (FG2 SCM). All FG noted a shift away from any religious and moral compass as a factor related to drug use. One teacher felt when people are "away from religion [it] leaves the person weak and does not have a strong will" (FG1 STF) whereas others felt the "religious institution has a responsibility" (FG3 STM). Likewise, "the concept of right and wrong, and all of that is because of [social] media that shows everything as fine and normal" (FG1 STF), instead of strong religious faith guiding people, “celebrities...talk about [addiction] normally in the media and this will help to spread it" (FG1 STF).

Poverty, overcrowding, and unemployment were believed to be a significant problem: "the camp is densely populated, you find a family that constitutes 8-10 individuals living in a half of a housing unit" (FG2 SCM). The school counsellor explained how "poverty is a big factor; it is a cause and a consequence at the same time. There is a percentage of residents in the camp who are originally from Gaza Strip [in Jordan, if you are not a Jordanian citizen you cannot get a license to work, just like the UK and rest of the world], those are unemployed, their conditions are very difficult, they suffer from poverty and need which leads them to try to get money in any possible way" (FG1 SCF). Therefore, the congested camps are "concentrated with unemployed youth" (FG2 STM) as well as high child labour rates because "students have to work on stalls and other places" (FG2 SCM) to help their parents. Displaced Palestinian children living in the UNRWA camps in Jordan were described as not having enough access 
to positive leisure activities and social networks. Participants raised concerns about children having "bad companions" (FG1 STF) with "the intruders of the camp from outside affecting the camp inside" (FG1 SPF). There was a "lack of entertainment" (FG1 SPF), and some described how children's natural curiosity could expose him/her to experimentation with substances "his goal is trying everything new with nothing to lose" (FG3 APF).

Across all three FG, while there was recognition that drug education and awareness programmes occur, there was a belief that these initiatives require scale up and expansion across the camps. One school principal observed the need to; "keep up with the awareness raising lectures that we are holding from school. The local community working with parents in cooperation with the school counsellor about the danger of drugs" (FG1 SPF). A teacher illustrated that this was problematic at times and highlighted "it is hard to get in touch with parents. Personally, I hold a meeting for parents where I invite around 100 parents, only 5 or 6 or 10 people would show up" (FG2 STM). Another school teacher raised a concern regarding how such sessions are delivered and described how: "I attended an awareness lecture on drugs, one of its main disadvantages was that he [the lecturer] explained how to prepare Joker in detail" (FG1 STF).

Solutions are multi-faceted and indicative of the need for prevention and support for those at risk, and affected

The FG discussed different strategies for solutions to help deter, and support those affected. In the first instance, safeguarding concerns were raised, and belief that greater resources were needed for supervision: "the social worker in school needs to devote herself more precisely" (FG1 SNF). A general practitioner felt that professionals should be actively "looking for children or asking the residents of the camp and other associations about the people and children at risk" (FG2 GPM). There was a perceived need for greater facilities provided for 
children experiencing trauma, with one suggestion to "make shelters in the camp, because a lot of children are abused with no one to turn to, so foster the child and protect him from the environment he is in" (FG1 SNF). Other strategies discussed in the FG included greater controls, with attention given to families at risk, for example several felt "it is necessary to have specialists visiting them and trying to address the problem within the family" (FG2 STM) and to "not only watch boys, watch their peers as well. And know exactly who they are dealing with" (FG3 APF). Many observed the need to build on the strengths of children and young people; "we can look for the skills they love and develop their talents and discover them, whether singing, drawing, imitating and encourage them to bring their thoughts to papers emptying of the inside" (FG1 SNF) and reward them for positive behaviour "in order to encourage them as both material and moral motivation" (FG2 STM). Alternative approaches included "in the summer vacation they can work on a memorizing Holy Quran, a drawing club, the worst thing is having spare time [excessively] because it creates the space for bad thoughts, so they should spend their time with positive things" (FG2 GPM) or "make use of their vacation and let them help with maintenance instead of sitting at home doing nothing in addition to integrating them in the service of society in order to [make] use [of] their energy" (FG2 STM). Participants in the health practitioners' focus group suggested the need for adult-child collaborative initiatives, with children at the centre of the decision-making process. One school nurse suggested: "make a parliament in the camp and take the children of the camp and discuss any negative phenomena and ask them what do they think and take their opinions, and to include awareness, you will be surprised with the creativity and ideas to be inspired by them... We need to give them a bigger position and value by giving them support and at the same time giving them the information and share the decision making with them" (FG3 SNF). Likewise, the process of shared learning and support was viewed as critical in helping young people deal with the familial and drug related trauma; "make group therapy in clinics, ..... sit 
together to benefit from the experiences and solutions of each other" (FG3 SNF). One school principal argued that "every year we have a school or developmental plan with an obligatory aspect that includes the relationship between the student and the local community regarding increasing awareness towards drugs. This is included in the annual plan" (FG2 SPM). A teacher felt strongly that awareness programmes should be "from a religious perspective because I feel when the subject comes from a religious perspective, it will more convincing" (FG2 STM). Although social media was perceived as a cause of increased drug use, it was further perceived by some in the group that health messages could be communicated well through "media, educational bulletins on television" (FG2 SJM).

The health practitioners' FG raised concerns around the need for mental health and rehabilitation centres for children, as well as greater community awareness of the location, accessibility and the types of services that these centres can provide. FG participants discussed how at present, there appeared to be a fear around confidentiality breaches and that should a person attend a centre for support, they would be reported to the police; "there is a centre for the treatment of addiction -free and confidential-Unfortunately, there is not enough marketing of this centre" (FG3 GPM). This was perceived to contribute to low community uptake.

All FG participants agreed that, in order to effectively tackle the issue of drug use and drug use disorder, there was a need to "return to the roots of the issue" (FG1 SCF). First, there was a need to address "both [the] social and economic situation" of camp inhabitants (FG2 STF). The denial of basic right to work, has underpinned unemployment, and was perceived to increase the temptation to engage in illegal activities; the "absence of jobs are factors, any student gets out tenth grade, even if he studied vocational or whatever, he will end up at home doing nothing, so the economic situation is a major factor" (FG2 STM). The economic crisis was also discussed as impacting on service delivered to camp communities "UNRWA is going through the most difficult stages as a result of reduced external support which impacts the 
services introduced by UNRWA, in addition to forcing it to shrink its staff whose people of Gaza are part of, this will affect them and increase unemployment which impacts their economic situation. So, unless UNRWA gets the support, it will not be able to give one" (FG2 SPF).

A collaborative response was called for across FG "we need to unite our efforts to get to a result" (FG2 $\mathrm{STM}$ ). One general practitioner highlighted the key players in this collaborative response. He described how vital the local community is in responding to this issue, stating how the community "plays a very important role in educating the youth together with the committee to improve the camp. It is necessary to play a role in awareness raising, creating additional activities for young people, making a playground and a place where they can spend their energies" (FG3 GPM). He emphasised the role of education and primary care providers in tackling mental health and reducing stigma "people have started to ask about the facilities available for treatment. The patient comes now and tells me that he would like to speak out, so the subject of the stigma is starting to vanish...there should be interdependence between education and health" (FG3 GPM).

\section{Discussion}

This study is part of a large Global Challenges funded project that aimed to understand the issue of internally and externally displaced Palestinian children's needs relating to trauma and vulnerabilities caused by substance use in the home (Al-Afifi et al., 2019). In addition to the impact of internal or external displacement or to be born into refuge, the impact of substance/drug use on these children, their siblings and their parents is significant (Al-Afifi et al., 2019; Van Hout et al., 2019). The FG in this project located in Jordan continue to paint a concerning picture of families being subjected to multiple pressures and exposed to a multitude of risks including use of drugs as a coping mechanism for trauma, stigmatisation for that drug 
use, restricted access to services, family breakdown, sexual abuse and criminality. The study is limited by its small-scale nature in two camps, and cannot be generalizable to other camps.

Previous studies have reported that internally displaced persons, refugees, excombatants, women, and youth in post-conflict situations are more likely to consume illicit drugs than are individuals in a stable society (Bhui \& Warfa, 2007; Hanna, 2017). Substance use among populations displaced by conflict is a neglected area of public health (Ezard et al., 2011; Habib et al., 2012). Multiplicity of factors are reported in our FG study as playing a possible role in the perceived increasing exposure to and availability of drugs in the two URNWA camps over the time. Of particular concern is the change of attitudes and societal fabric of the camp over time, with "outsiders" entering the camp and introducing substances to Palestinian youth inhabitants. Alongside this occurrence is the increasing exposure of children, youth and young adults to social media and the internet, all serving to desensitise them to the harms of substance/drug use. This may also raise the question of whether or not the popularity of drugs has genuinely increased, leading to general desensitisation of what is a highly stigmatised behaviour in the Arab world, or instead that as people become more educated with time and more open to the outside world, through means of technology and the internet, they also become more open and accepting of new behaviours they were not aware of previously (United Nations Office on Drugs and Crime (UNODC), 2012). It also highlights the need for high quality accessible information for frontline staff (health practitioners and educators) to prevent reliance on miscommunication and hearsay in relation to prevalence, drug markets, demonization and the most negative of outcomes. Of note was how "playing with terms" or beautifying the names of substances in announcements in restaurants and cafes might increase experimentation and use (for example; the use of "ahla nafas" meaning in Arabic the 'sweetest breath' or 'inhale with joy' for wastepipe), see (Du Plessis, 2008). Refugee camps are connected with Jordanian societal norms as a whole, and hence exposed to national trends in 
substance use. Moreover, The growing popularity of waterpipes in Jordan, known locally as Shisha or Argile, among women and teenagers has led to a huge expansion in the number of waterpipe cafes, which can be a pathway toward use and poly consumption of other substances (Dar-Odeh et al., 2013; Burki, 2019). In a study conducted on 1050 school students (age 1118 years old) in Jordan, rates of waterpipe-only and cigarette-only smoking were $7 \%$ and $3 \%$, respectively, and were similar for boys and girls. In contrast, the rate of dual use was much higher than for single product use and was double in girls compared to boys (34\% vs. $17 \%$; Alzyoud et al., 2014). Jordan also has the highest number of smokers in the Middle East, ranking second place globally, after Indonesia. (Ministry of Health, 2019). Around 70\% of Jordanian men are reported to be smokers and laws prohibiting smoking in public places are widely disregarded (Burki, 2019). Given the connection between camp and community, this can explain the high levels of cigarette smoking reported among all age groups in the camp. Similarly, in the West Bank, a study conducted on 835 male teenagers aged 15-16 years reported that $50.6 \%$ of refugee camp teenagers were current tobacco smokers, slightly higher than that reported by city teenagers $(40.3 \%)$ and those living in villages (38.4\%) (Damiri, 2019).

Our study shows that the Palestinian refugee population in Jordan are increasingly vulnerable to drug availability and drug activity due to their marginalised situation within the camps and their general lack of opportunity which slowly but persistently undermines the sense of identity which many once had. Similar has been reported in the West Bank and Gaza (Massad et al., 2016; Al-Afifi et al., 2015; 2019; Damiri et al., 2018a:b:2019; Van Hout et al., 2019). There FGs however have highlighted both divergence and convergence around perspectives on the issue of substance/drug use in the camps, and how this affects children, families and communities. The teachers appeared confident that there was no drug use in their schools, and that they had not seen any problems related to drug use. This was contrary to the 
views of health care professionals in Al-Zarqa camp. Such contrasting insights may be due to the difference in occupation/work setting of participants. Health care professionals would encounter such "problems" (for example substance use, gender-violence and mental health issues) when camp individuals and families visit the health care facility asking for help. In so doing their narratives around the situation in schools is based on their perceptions, only what they "hear of" happening at schools, whereas at Al-Wehdat camp, the participants were teachers, school principals and counsellors who would give a clear and more realistic picture of the situation at schools.

The study highlights several areas for strategic response within the camps. There was an agreement from participants on the importance of the role that NGOs play in managing this issue, especially at a time when civil society is considered by some to be at breaking point and the recent 'right to return' protests were described by the United Nations as 'a call for help from a population in despair' (United Nations/The question of Palestine, 2018). Since 2017, UNRWA has lost more than half of its funding from the US, and President Trump's recently announced "peace plan" for the region has been denounced by many in the international community as being a smokescreen for annexation. Moreover it crucially removes 'the right of return' for Palestinian refugees, which would in effect terminate UNWRA's whole programme. This in itself will add further stress and sense of loss to an already traumatised population which may then inadvertently cause a further rise in self-medication in the form of substance use. In refugee populations this is strongly associated with mental illness (Amosu et al., 2016). In 2017, The Mental Health and Psychosocial Support (MHPSS) Framework was established in UNRWA camps across the region to facilitate greater coherence, consistency and quality of UNRWA MHPSS interventions and their impact across the Agency, in order to protect and improve the mental health and psychosocial well-being of Palestine refugees (UNRWA /Mental Health and Psychosocial Support Framework, 2017). However, the 
financial constraints placed on UNRWA in 2018 make expanding this kind of activity difficult (United Nations/ the question of Palestine, 2018), and indeed the existential risk now hanging over UNRWA will further inhibit the organisation's ability to plan for the future, potentially only being able to offer a reactive response to drug use rather than implementing a preventative public health model. In the absence of adequate resources in place to prevent, promote youth resilience, support families and treat those affected, Palestinian communities will be increasingly disadvantaged. The study underscores that whilst camp exposure has increased, stigma of drug use, and of dependence, as well as concerns around treatment confidentiality remains. This has direct effects on help seeking behaviours (Yasin et al., 2020; Crapanzano et al., 2019), despite the fact that under Jordanian law the dependent drug user is deemed a patient not a criminal (de La Rochefoucauld, 2014). This paper recognizes that action is needed now to prevent further escalation of the issues concerned.

\section{Conclusion}

Displacement, conflict, trauma, unemployment and poverty are but some of the myriad factors that influence Palestinian refugee mental health, and include drug abuse and addiction in the home. This unique study whilst small-scale represents a first step to understanding the issue in two Jordanian UNRWA camps. It has illustrated the perspectives and experiences of frontline health and education professionals in two UNRWA camps and has described the effect of substance/drug use and drug use disorder on youth and families living in these camps. It paints a concerning picture of how this issue impacts on Palestinian refugees, already subjected to multiple pressures, stigmas, risks and harms relating to their situation, and particularly how drug use disorder further exacerbates their mental health and individual/familial support needs. It underscores the urgent need for a united and strategic response underpinned by drug education and prevention, promotion of youth resilience, family support, reduction of harm, 
and treatment initiatives. For an evidence based approach to have credibility in the Jordanian camp communities, there is a need for further surveillance and research activity to provide accurate, factual information, along with robust epidemiological data, relating to the extent, characteristics and harms associated with drug use. The role of NGOs in supporting a holistic response spanning schools, family and community is paramount. Threats to UNRWA from the current political climate mean that this issue may be exacerbated and have fewer resources at a time when more are needed.

\section{Funding}

This study was funded by The Global Challenges Research Fund (GCRF) Small Grants Scheme 2019, Liverpool John Liverpool John Moore’s University, 2019. Grant holder, Professor Marie Claire Van Hout.

\section{Acknowledgement}

The authors would like to thank staff of UNRWA Health and Education programmes for their great support and cooperation. Special thanks to Dr. Sieta Akihiro, Director of Health UNRWA for his great facilitation of the project. Also, we would like to thank all twenty participants in the focus groups for their time and effort, without which this project wouldn't have seen the light. 


\section{References}

Al-Afifi, M., Abushams, L., Sakka, M., Shehada, M., Afifi, R., Alloush, M., ... Whitfield, M. (2019). Perspectives of Frontline Professionals on Palestinian Children Living with Sibling and Parental Drug Use in the West Bank and Gaza Strip. International Journal of Mental Health and Addiction, 1-16.

Al-Afifi, M. F., Sakka, M., Shehada, M., \& Afifi, R. (2015). Effect of Gaza 2014 war on use of smoking, tramadol, and psychoactive drugs among university students. Retrieved February 1, 2020 from https://www.drugabuse.gov/international/abstracts/effect-gaza2014-war-use-smoking-tramadol-psychoactive-drugs-among-university-students

Al-ghzawi, H. M., ALBashtawy, M., Azzeghaiby, S. N., \& Alzoghaibi, I. N. (2014). The impact of wars and conflicts on mental health of Arab population. International Journal of Humanities and Social Science, 4, 237-242.

Al-Husseini, A., Abu-Farha, R., Van Hout, M. C., \& Wazaify, M. (2019). Community pharmacists experience of pregabalin abuse and misuse: A quantitative study from Jordan. Journal of Substance Use, 24(3), 273-279.

Al-Husseini, A., Abu-Farha, R., Wazaify, M., \& Van Hout, M. C. (2018a). Pregabalin dispensing patterns in Amman-Jordan: An observational study from community pharmacies. Saudi Pharmaceutical Journal, 26(3), 306-310.

Al-Husseini, A., Wazaify, M., \& Van Hout, M. C. (2018b). Pregabalin misuse and abuse in Jordan: A qualitative study of user experiences. International Journal of Mental Health and Addiction, 16(3), 642-654.

Al-Khalaileh, W., Abu Farha, R., Wazaify, M., \& Van Hout, M. C. (2019). Opthalmic drug abuse and misuse in Jordan: An Observational Study from Community Pharmacies in Amman. Research in Social and Administrative Pharmacy, 15(8), 943-948.

Al- Krenawi, A., Lev- Wiesel, R., \& Mahmud, A. S. (2007). Psychological symptomatology 
among Palestinian adolescents living with political violence. Child and Adolescent Mental Health, 12(1), 27-31.

Alzyoud, S., Kheirallah, K. A., Weglicki, L. S., Ward, K. D., Al-Khawaldeh, A., \& Shotar, A. (2014). Tobacco smoking status and perception of health among a sample of Jordanian students. International Journal of Environmental Research and Public Health, 11(7), 7022-7035.

Amosu, S. M., Onifade, P. O., \& Adamson, T. A. (2016). Psychoactive substance use and general mental health among refugees in a Nigerian camp. Journal of Substance Use, 21(3), 230-236.

Arfken, C. L., \& Ahmed, S. (2016). Ten years of substance use research in Muslim populations: Where do we go from here? Journal of Muslim Mental Health, 10(1). https://doi.org/http://dx.doi.org/10.3998/jmmh.10381607.0010.103

Bhui, K., \& Warfa, N. (2007). Drug consumption in conflict zones in Somalia. PLoS Medicine, 4(12).

Braun, V., \& Clarke, V. (2006). Using thematic analysis in psychology. Qualitative Research in Psychology, 3(2), 77-101.

Braun, V., Clarke, V., Hayfield, N., \& Terry, G. (2019). Thematic analysis. Handbook of Research Methods in Health Social Sciences, 843-860.

Burki, T. K. (2019). Tobacco control in Jordan. The Lancet Respiratory Medicine, 7(5), 386.

Clarke, V., \& Braun, V. (2018). Using thematic analysis in counselling and psychotherapy research: A critical reflection. Counselling and Psychotherapy Research, 18(2), 107110.

Crapanzano, K. A., Hammarlund, R., Ahmad, B., Hunsinger, N., \& Kullar, R. (2019). The association between perceived stigma and substance use disorder treatment outcomes: A review. Substance Abuse and Rehabilitation, 10, 1. 
Damiri, B., Isra'A, S., \& Aghbar, M. (2018a). Pattern of substance use among schoolchildren in Palestine: a cross-sectional study. Egyptian Journal of Forensic Sciences, 8(1), 59.

Damiri, B. R. (2019). The Use of Psychoactive Substances in a Conflict Area in the West Bank: Drug Use Risk Factors and Practices in Palestinian Refugee Camps. International Journal of Mental Health and Addiction, 1-14.

Damiri, B., Sayeh, W., Odeh, M., \& Musmar, H. (2018b). Drug use and possession, emerging of new psychoactive substances in the West Bank, Palestine. Egyptian Journal of Forensic Sciences, 8(1), 42.

Dar-Odeh, N. S., Beyari, M. M., Al-Abdalla, M., Al-Shayab, M. H., Abdulrazzaq, W. S., Jarar, S., ... Abu-Hammad, O. A. (2013). The use of unconventional substances and tools in narghile smoking; a pilot study in Jordan. Journal of Advances in Medicine and Medical Research, 2042-2053.

Defence for Children International/ Palestine section. (2007). Children In Street: The Palestinian Case. Retrieved July 2, 2019, from https://arabic.dcipalestine.org/ dcipal/sites/arabic.dci-palestine.org/files/childreninthestreetarabic.pdf de La Rochefoucauld, M. (2014). Jordan Drug Situation and Policy. Retrieved February 1, 2020, from https://rm.coe.int/drug-situation-and-policy-by-matthieu-de-larochefoucauld/168075f2a7

Du Plessis, E. (2008). The advertised mind: Ground-breaking insights into how our brains respond to advertising. Millward Brown Publishers, London, UK.

Dupire, C. (2018, March 26). Local organisation tackles drug abuse in Al Husn refugee camp. The Jordan Times. Retrieved February 9, 2020, from http://jordantimes.com/news/local/local-organisation-tackles-drug-abuse-al-husnrefugee-camp

Elbedour, S., Onwuegbuzie, A. J., Ghannam, J., Whitcome, J. A., \& Hein, F. A. (2007). Post- 
traumatic stress disorder, depression, and anxiety among Gaza Strip adolescents in the wake of the second Uprising (Intifada). Child Abuse \& Neglect, 31(7), 719-729.

Ezard, N., Oppenheimer, E., Burton, A., Schilperoord, M., Macdonald, D., Adelekan, M., ... van Ommeren, M. (2011). Six rapid assessments of alcohol and other substance use in populations displaced by conflict. Conflict and Health, 5(1), 1.

Glick, P., Al Khammash, U., Shaheen, M., Brown, R., Goutam, P., Karam, R., ... Massad, S. (2018). Health risk behaviours of Palestinian youth: findings from a representative survey. EMHJ-Eastern Mediterranean Health Journal, 24(02), 127-136.

Habib, R. R., Seyfert, K., \& Hojeij, S. (2012). Health and living conditions of Palestinian refugees residing in camps and gatherings in Lebanon: a cross-sectional survey. The Lancet, 380, S3.

Hanna, F. B. (2017). Alcohol and substance use in humanitarian and postconflict situations. Eastern Mediterranean Health Journal, 23(3).

Kallio, H., Pietilä, A., Johnson, M., \& Kangasniemi, M. (2016). Systematic methodological review: developing a framework for a qualitative semi- structured interview guide. Journal of Advanced Nursing, 72(12), 2954-2965.

Khamis, V. (2005). Post-traumatic stress disorder among school age Palestinian children. Child Abuse \& Neglect, 29(1), 81-95.

Kitamura, A., Jimba, M., McCahey, J., Paolucci, G., Shah, S., Hababeh, M., ... Seita, A. (2018). Health and dignity of Palestine refugees at stake: a need for international response to sustain crucial life services at UNRWA. The Lancet, 392(10165), 27362744.

Massad, S. G., Shaheen, M., Karam, R., Brown, R., Glick, P., Linnemay, S., \& Khammash, U. (2016). Substance use among Palestinian youth in the West Bank, Palestine: a qualitative investigation. BMC Public Health, 16(1), 800. 
Ministry of Health/ Health Awareness Department. Who smokes most? Jordan possibly next country to rank in first place globally. (2019, January 22). Retrieved February 5, 2020, from https://en.royanews.tv/news/16503/2019-01-22

Nowell, L. S., Norris, J. M., White, D. E., \& Moules, N. J. (2017). Thematic analysis: striving to meet the trustworthiness criteria. International Journal of Qualitative Methods, 16(1), 1609406917733847.

Palestinian National Institute of Public Health. (2017a). Estimating the Extent of Illicit Drug Use in Palestine. Retrieved July 2, 2019, from https://www.unodc.org/documents/middleeastandnorthafrica/Publications/Estimating_th e_Extent_of_Illicit_Drug_Use_in_Palestine.pdf

Palestinian National Institute of Public Health. (2017b). Illicit Drug Use in Palestine. Retrieved October 5, 2019, from https://www.unodc.org/documents/publications/Illicit_Drug_Use_in_Palestine.pdf Santoro, A., Abu-Rmeileh, N., Khader, A., Seita, A., \& McKee, M. (2016). Primary healthcare reform in the United Nations Relief and Works Agency for Palestine Refugees in the Near East. Eastern Mediterranean Health Journal, 22(6), 417-421.

Smithson, J. (2000). Using and analysing focus groups: limitations and possibilities. International Journal of Social Research Methodology, 3(2), 103-119.

Sweileh, W. M., Arafat, R. T., Al-Khyat, L. S., Al-Masri, D. M., \& Jaradat, N. A. (2004). A pilot study to investigate over-the-counter drug abuse and misuse in Palestine. Saudi Medical Journal, 25(12), 2029-2032.

Thabet, A. A. M., \& Dajani, J. K. (2012). Substance abuse among Palestinians in the West Bank and Gaza Strip. Arab Journal of Psychological Science, 36, 76-78.

United Nations/ The question of Palestine. (2018). UNRWA Faces Greatest Financial Crisis in Its History Following 2018 Funding Cuts, Commissioner-General Tells Fourth 
Committee - Press Release. Retrieved February 5, 2020, from

https://www.un.org/unispal/document/unrwa-faces-greatest-financial-crisis-in-its-

history-following-2018-funding-cuts-commissioner\%E2\%80\%91general-tells-fourthcommittee-press-release/

United Nations Office on Drugs and Crime (UNODC). (2019). Independent Evaluation of PSEY13. Supporting the establishment of evidence-based drug dependence treatment and rehabilitation system for the Palestine National Rehabilitation Centre. Retrieved October 9, 2019, from https://www.unodc.org/documents/evaluation/Independent_Project_Evaluations/2019/P SEY13_Final_Independent_Project_Evaluation_Jan_2019.pdf

United Nations Office on Drugs and Crime (UNODC). (2012). World Drug Report, Chapter 2: The Contemporary Drug problem: Characteristics, Patterns and Driving factors. Retrieved February 9, 2020, from https://www.unodc.org/documents/data-andanalysis/WDR2012/WDR_2012_Chapter2.pdf

United Nations Relief and Works Agency (UNRWA). (2017). Mental Health and Psychosocial Support Framework. Retrieved January 31, 2020, from https://www.unrwa.org/resources/about-unrwa/mental-health-and-psychosocial-supportframework.

United Nations Relief and Works Agency (UNRWA). (2020a). Palestine Refugees. Available at www.unrwa.org/palestine-refugees

United Nations Relief and Works Agency (UNRWA). (2020b). Where we work. Jordan. Available at www.unrwa.org/where-we-work/jordan 
Van Hout, M. C., Al-Afifi, M. F., Abushams, L., Kewley, S., Quigg, Z., Whitfield, M., ... Wazaify, M. (2019). Palestinian Children's Experiences of Drug Abuse in the Home in the Occupied Territories of Palestine: a Scoping Review of Extant Literature. International Journal of Mental Health and Addiction, 1-14. https://doi.org/https://doi.org/10.1007/s11469-019-00085-2

Wazaify, M., Alali, M. B., Yousef, M. A., \& Qammaz, S. (2017). Ophthalmic drops abuse in community pharmacy setting: A cross-sectional study from Jordan. Journal of Substance Use, 22(6), 656-660.

Yasin, H., Bulatova, N., Wazaify, M. (2020). Patterns of Substance Use among Patients in Addiction Rehabilitation in Jordan. Substance Use and Misuse, online Feb 3:1-10. doi: 10.1080/10826084.2020.1722697. 
Table I: Demographics of focus group and participants occupation and gender

Focus Group and

Camp

Focus Group $1 \mathrm{Al}$ -

Wehdat

Focus Group $2 \mathrm{Al}$ -

Wehdat

Focus Group $3 \mathrm{Al}$ -

Zarqa

\section{Sample Participant occupation and} size

7 gender

School Teacher $(n=5)$ female School Counsellor $(n=1)$ female School Principle $(n=1)$ female

$7 \quad$ School Teacher $(n=4)$ male School Counsellor $(n=1)$ male School Principle $(n=1)$ male School Janitor $(n=1)$ male

6
Acronym used in results

(FG1STF)

(FG1 SCF)

(FG1 SPF)

(FG2 STM)

(FG2 SCM)

(FG2 SPM)

(FG2 SJM)

(FG3 GPM)

(FG3 PAF)

(FG3 SNF)

(FG3 PNF)
Duration

(minutes)

64

68

75
Pharmacy Assistant $(n=1)$ female

School Nurse $(n=1)$ female

Staff and practice nurse $(n=2)$ female 
Table II: Themes and sub-themes across three focus groups in Jordan

Themes and sub-themes across three focus groups in Jordan

\section{Superordinate themes}

1) Access to drugs was perceived to be relatively easy in the Jordanian UNRWA camps

2) Attitudes towards drugs appear to have desensitised, yet stigma persists

3) Families of drug users are affected by fear, social and economic poverty, with significant physical and psychological cost to children

4) Causes of substance/drug use disorder in Palestinian communities living in Jordanian UNRWA camps is multifactorial

\section{Sub themes}

- Access to drugs on UNRWA camps is easy, children are targeted and exploited within and outside of the family, drugs are a weapon used to harm others (FG1, FG3)

- Drug dealing is not witnessed in school time, but outsiders come to school yards (FG1, FG2)

- The problem is representative across Jordan, but substance use is not the only challenge (All)

- The problem is widely publicised in social media in which children have great knowledge and access, but the issue remains hidden and stigmatised (FG3)

- Boys have more opportunity to access drugs, but where there is wealth, girls are equally prevalent users (All)

- Drug use disorder, drug use and drug dealing is perceived to be increasingly prevalent.

- Drugs are brought into camp and marketed, and innovative ways to increase the user base are observed (All)

- Peoples' attitudes toward drug use in the community have become desensitised over time, but with stigma associated with help-seeking for those affected.

FG3)

(FG1,

- Children experience psychological and physical problems, risk sexual and domestic abuse, suffer secondary effects of drugs, drop out of school and mimic drug use (All)

- Families of drug users feel stigmatised and with low awareness of where to seek help (FG2, FG3)

- Families of drug users breakdown socially and economically, they live in fear and distress and often turn to crime (All)

- Family breakdown, poor parenting (AlI), lack of positive activities and social networks for children, with outsiders in camps, children's natural curiosity (All)

- Insufficient or inappropriate drug education and awareness or even an over awareness (All)

- Poverty, overcrowding, and unemployment (All)

- Shift in the religious and moral compass (All) 
5) Solutions are multi-faceted and indicative of the need for prevention and support for those at risk, and affected
- Children at risk need protection and support and all should have opportunity to access positive and health activities out of school time in holidays, with incentives for positive behaviour (FG2, FG3)

- Participatory initiatives with children including drug and health education and awareness interventions from a range of perspectives e.g. religious, biological, social and to all stakeholders (All)

- Beyond the root of problem which is poverty, requiring a solution must be multifaceted and goes beyond UNRWA (All)

- The rehabilitation centre in the camp and mental health clinics provides psychological support, and needs to expand to support children and involve drug use disorders too (FG1, FG3)

- Support/treatment services need to be better signposted (All) 
Table III: Substances most frequently discussed across focus groups (in bold reported most used)

Substances most frequently discussed across focus groups

Alcohol

Alcohol disinfectant

Antihistamines

Captagon (fenethylline)

Cough syrup

Dextromethorphan

Joker (synthetic cannabinoids)

Lyrica (pregabalin)

Mainly pills

Panadol (paracetamol)

Prazin (alprazolam)

Prescribed sedatives and painkillers

Revotril (clonazepam)

Rivanin (paracetamol)

Saliba (street name for clonazepam)

Smoking tobacco cigarettes

Tramal (tramadol)

Cannabis 


\section{Response to Reviewers:}

First of all, we would like to thank the editor and both reviewers for their time, effort and valuable comments.

The authors have addressed all comments as follows (all changes are either in yellow highlight or strikethrough):

\section{Reviewer \#1:}

Dear Dr. Masood,

Thank you for considering me as a reviewer for this paper entitled "Perspectives of frontline professionals on Palestinian children living with sibling and parental drug use in the UNRWA camps, Jordan". In my opinion, the paper is well written and contributes to the existing knowledge. I could not find any logical errors in the presentation and the approaches used. The following points may be considered while revising the article. - Abstract (Page1): Five million Palestinians live in the oPt (2 million in Gaza, with 66.2\% in refugee camps, and 3 million in the West Bank and Jerusalem, with 26.6\% in refugee camps). A further 2.2 million Palestinians are displaced and living in the ten UNRWA refugee camps in Jordan. Citation needed.

>> This sentence has been deleted upon request of reviewer-2

- Page 3, Lines (2-8) were just stated in abstract.

>> Sentence deleted.

-Page 3, Lines 5. Citation needed.

-Page 3, Lines 10. Citation needed.

- Page 3, Lines 12. Citation needed.

-Page 3, Lines 17. Citation needed.

-Page 3, Lines 17. Citation needed.

- Page 4, Line 9. Please follow the APA format in text citation.

- Page 5, Line 11. Please follow the APA format in text citation.

- Page 22, Line 4. Citation needed.

>> All citations have been added in place as requested. APA format have been addressed.

- Introduction: The effect of drug use on Palestinian refugee children needs to be more clarified and linking within the existing literature. 
>> This paragraph has been added as requested in pages 4-5:

"The effect of drug use on children and their families living in the Palestinian refugee camps is far-reaching and includes familial stigma and community isolation, dysfunction, early school leaving and maladaptive child development (Van Hout et al., 2019). Research conducted by the team in 2019 in the oPt has underscored how they are vulnerable of children and young people at risk of substance use (including drugs), and are vulnerable to physical and sexual abuse, exploitation in drug trafficking, and at risk of becoming dependent users themselves (Al-Afifi et al., 2015; Van Hout et al., 2019; (Al-Afifi et al., 2019; United Nations Office on Drugs and Crime (UNODC), 2019)."

\section{Reviewer 2: (THE COMMENNTS WERE IMPEDED WITHIN pdf)}

- Abstract: No need for this sentence in the abstract and Introduction:

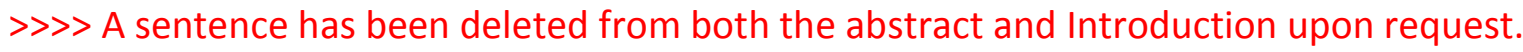
"Five million Palestinians live in the oPt (2 million in Gaza, with $66.2 \%$ in refugee camps, and 3 million in the West Bank and Jerusalem, with 26.6\% in refugee camps). A further 2.2 million Palestinians are displaced and living in the ten UNRWA refugee camps in Jordan."

- Introduction, page 4, line 8: Need citation > > A citation (UNRWA, 2020a) has been added to this sentence "UNRWA is the oldest....." as requested.

- AUTHOR RESPONSE: Page 4: Variables have been separated as requested: "A reported rise in substance/drug use, injecting use and drug use disorder in the oPt (West Bank and Gaza) has been observed in recent times and related to exposure to trauma, poverty, unemployment, fragmentation of Palestinian families and community stress"

- AUTHOR RESPONSE: Pages 6-7: This sentence has been added to describe the rationale and uniqueness of the study as requsted: "To date these has not been any published study on the situation of drug use and drug use disorder in the Jordanian UNRWA camps. Our study offers a preliminary investigation of the issue and how it affected Palestinian communities who live there, in order to understand their needs and inform the strategic response."

- my recommendation to divide the discussion to the important findings, and need to discuss them separately according to sub- topics in the results section >>> AUTHOR RESPONSE: The results themes are 1)Access to drugs was perceived to be relatively easy in the camps; 2) Attitudes towards drugs appear to have desensitised, yet stigma persists; 3) Families of drug users are affected by fear, social and economic poverty, with significant physical and psychological cost to children; 4) Causes of substance/drug 
use in Palestinian communities living in Jordanian UNRWA camps is multifactorial; 5)

Solutions are multi-faceted and indicative of the need for prevention and support for those at risk, and affected.

> We present the discussion in the same themes, relating to change in in exposure, availability and desensitisation toward drugs, and Jordanian societal trends in substance use (para 2); the differences in perspective on the issue, and the consequences of this phenomenon (para 3), and the strategic responses and context for reform (para 4).

- Conclusions: there is need to connect these conclusions with mental health >> AUTHOR RESPONSE: ADDRESSED

- Conclusions: there is need to write the study limitations, need to expand the conclusions of the study and its implications, in addition to recommendations for continuing studies >> AUTHOR RESPONSE: ADDRESSED

- References: journals and books need tobe italic. There is a need to check carefully this section

- $\quad$ > A AUTHOR RESPONSE: ADDRESSED

- $\quad$ > Also 2 additional references: UNRWA, 2020a and UNRWA, 2020b have been added.

- With regard to Tables: APA style: without vertical lines and must be just with three horizontal lines

- $\quad$ > > > > AUTHOR RESPONSE Addressed 
Authors have no conflict of interest to report.

Disclosure of Interest Form

Authors have no conflict of interest to report.

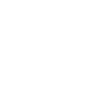

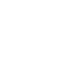

Disclosure of Interest Fom

no conflict of intere

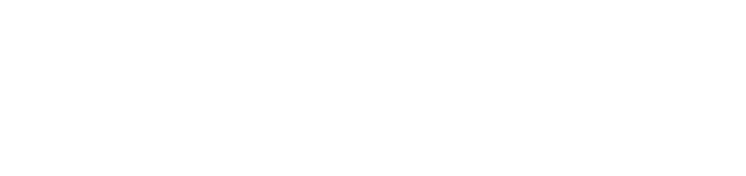

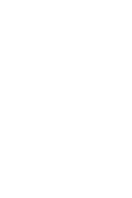

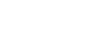

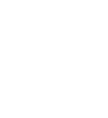

(n)

(1)

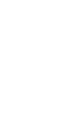

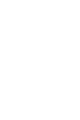

